\title{
Macular Abnormality after Successful Surgery for Idiopathic Macular Hole Assessed Using Optical Coherence Tomography
}

\author{
Nazimul Hussain ${ }^{1 *}$ and Anjli Hussain ${ }^{2}$ \\ ${ }^{1}$ Department of Ophthalmology, Al Zahra Hospital, United Arab Emirates \\ ${ }^{2}$ Medical Retina, Al Mamzar Al Khan, United Arab Emirates \\ *Corresponding author: Nazimul Hussain, Department of Ophthalmology, Al Zahra Hospital, PO Box 3499, Sharjah, United Arab Emirates
}

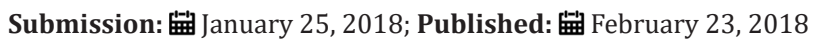

\begin{abstract}
Purpose: Macular changes following Internal Limiting Membrane peeling after successful Macular hole closure using optical coherence tomography.

Methods: 5 eyes of 5 patients were included in the study. The inclusion criteria were idiopathic full thickness macular hole and completed at least 6 months follow up. All patients underwent optical coherence tomography assessment before and after surgery until 6 months. Macular thickness and morphology map was analyzed before and after surgery.
\end{abstract}

Results: There were 3 males and 2 females. The age range from 45 to 59 years. Conspicuous irregular surface of the inner retina on Optical Coherence Tomography surface topography was evident in all eyes at 6 months. This was also associated with downward slope of the temporal macula seen on surface topography. There was trend towards decrease in subfield thickness especially in the T1, S1, I1 and N1 6 months after surgery. The average decrease was -60.4 microns in T1, -20.4 microns in S1, -13.0 microns in I1 and -23.4 microns in N1.

Conclusion: In this small case series brilliant blue assisted ILM peeling after successful macular hole closure showed evidence of decrease in macular thickness in all first subfield quadrant and downward slope of the temporal macula as well as conspicuous irregularity of the inner retina.

Keywords: Macular hole; Internal limiting membrane; Optical coherence tomography; Macular morphology; Macular thinning

\section{Introduction}

Pars plana vitrectomy and internal limiting membrane peeling (ILM) is the standard of management for full thickness macular hole. After the introduction of ILM peeling, the success rate of surgical management of macular hole has improved tremendously. Several studies have shown that internal limiting membrane (ILM) peeling in macular hole surgery causes changes in the macular thickness and decrease in retinal sensitivity [1-10].

Advances in optical coherence tomography (OCT) technology over the years have made possible to assess the macular morphology and thickness more accurately. It has also made possible to study the structures in the layer of the retina more accurately. With this objective, a study of macular changes after brilliant blue assisted ILM peeling for idiopathic macular hole was done using optical coherence tomography (OCT).

\section{Materials and Methods}

A retrospective interventional short case series of 5 eyes of 5 patients. There were 3 males and 2 females. The age range from 45 to 59 years. The inclusion criteria were idiopathic macular hole, who underwent brilliant blue (BBG) assisted ILM peeling with non-expansile gas injection and patients who completed at least 6 months of follow up without any evidence of any retinopathy that may affect the outcome of the surgery.

All patients underwent pars plana vitrectomy using 23G trocar - cannula system. All cases operated by single surgeon. After induction of posterior vitreous detachment, pars plana vitrectomy was completed. Brilliant Blue (BBG) was used to stain the ILM followed by peeling of ILM using forceps starting from the temporal area of macula. Non-expansile gas (SF6) was used at the end of surgery. All patients were instructed face down position 4-6 hours a day for 5-7 days.

Optical Coherence Tomography (Topcon 3D OCT-2000) was performed before and after surgery on month 1, month 3 and month 6. Macular topography map and macular thickness map was analyzed. Each 8 subfield quadrant of macular thickness map surrounding the central subfield quadrant was designated as 
Temporal (T1/T2); Superior (S1/S2); Inferior (I1/I2) and Nasal (N1/N2) (Table 1). Hospital review board consent was taken for this retrospective study.

\section{Results}

OCT surface topography map showed characteristic irregular surface of the inner retina seen in all eyes at 6 months and a trend towards downward slope was evident in the temporal part of the macula (Figure 1). Macular thickness map showed a trend towards decrease in subfield thickness especially in the T1, S1, I1 and N1 segments at the end of 6 months follow up. The average subfield retinal thickness decrease in the first subfield was -60.4 microns in T1, -20.4 microns in S1, -13.0 microns in I1 and -23.4 microns in N1 (Figure 2) at the end of 6 months follow up. The average second subfield thickness change was +6.6 microns (T2); -4.2 microns (S2); -13.0 microns (I2) and -2.0 microns (N2) (Figure 3).

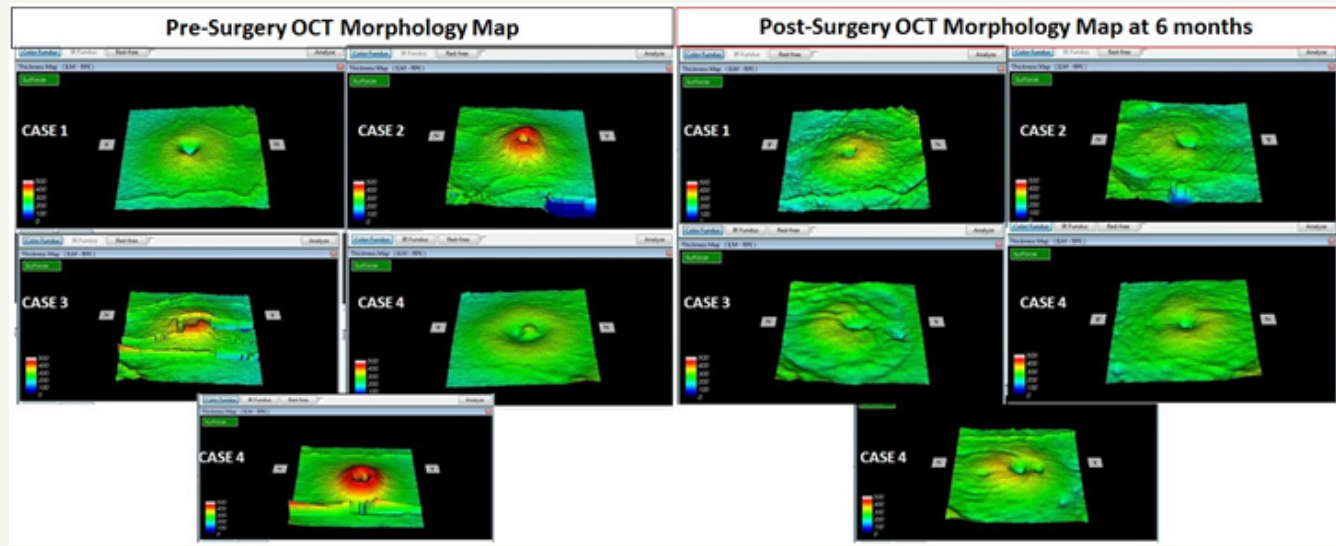

Figure 1: Shows the topographic morphology on OCT pre-surgery and post operative appearance at the end of 6 months.

\section{Case 1}

45 year old male with initial visual acuity of 6/36 in right eye. Post-surgery 6 months follow up, macular hole was closed and visual acuity improved to 6/9. Post- surgery 6 months OCT showed characteristic surface irregularity conspicuous mainly in the temporal macula (Figure 1). The first subfield thickness difference from the baseline until 6 months was -80 microns (T1), -11 microns (S1), 2 microns (I1) and 9 microns (N1) (Figure 2).

\section{AVERAGE SUBFIELD THICKNESS 6 MONTHS AFTER SURGERY IN FIRST QUADRANT SUBFIELD}

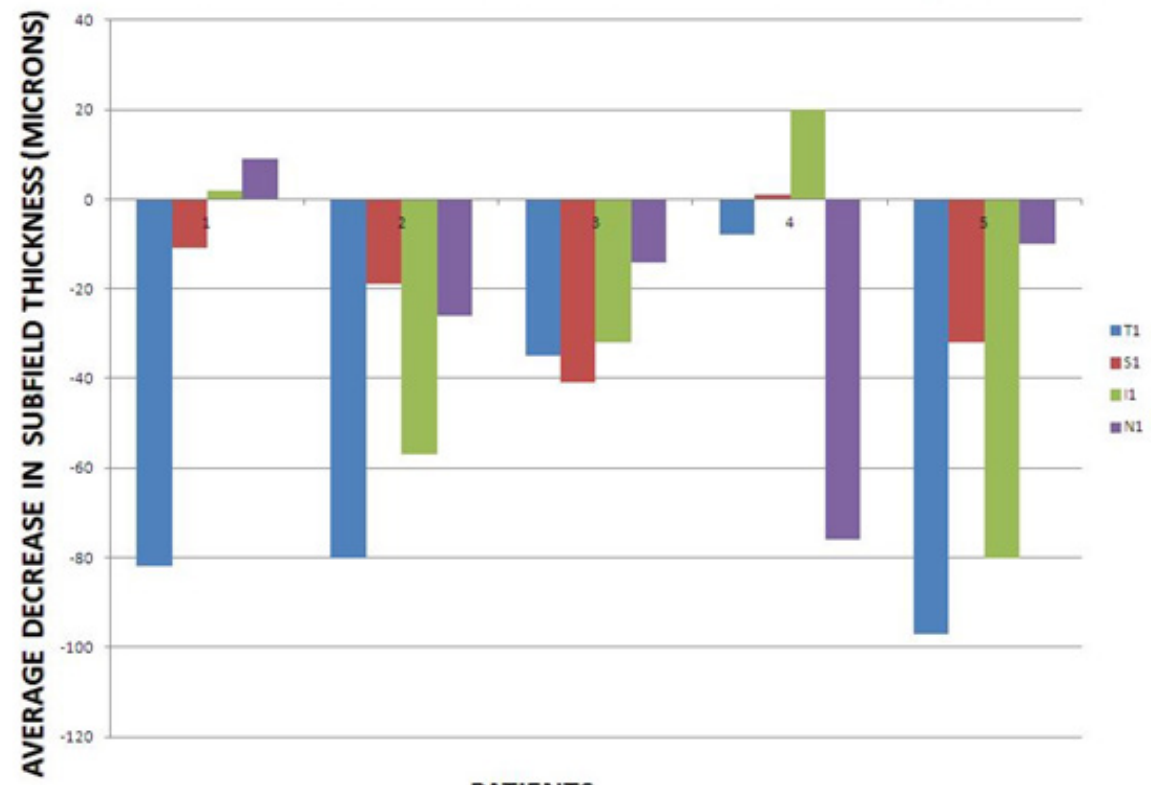

PATIENTS

Figure 2: Shows the topographic morphology on OCT pre-surgery and post operative appearance at the end of 6 months.

\section{Case 2}

52 year old male had preoperative visual acuity of $6 / 24$ and 6 month post-surgery visual acuity was 6/6. OCT topographic map showing temporal irregularity of inner retinal surface (Figure 1) and first subfield thickness change at 6 months from baseline was - 80 microns (T1), -19 microns (S1), -57 microns (I1) and -26 microns (N1) (Figure 2). 


\section{Case 3}

51 year old female in left eye had pre-operative vision of $6 / 30$ which improved to $6 / 12$ at the end of 6 months. OCT topographic mapping showed similar temporal irregularity (Figure 1) and first subfield thickness change from baseline after surgery at 6 months was -35 microns (T1), -41 microns (S1), -32 microns (I1) and -14 microns (N1) (Figure 2).

\section{Case 4}

56 year old female, in right eye had initial visual acuity of counting finger 1.5 meters achieved final visual acuity of $6 / 15$ at 6 months. Topographic morphology showed characteristic surface irregularity in the temporal quadrant (Figure 1). The first subfield thickness from the baseline until 6 months was -8 microns (T1), 1 microns (S1), 20 microns (I1) and -76 microns (N1) (Figure 3).

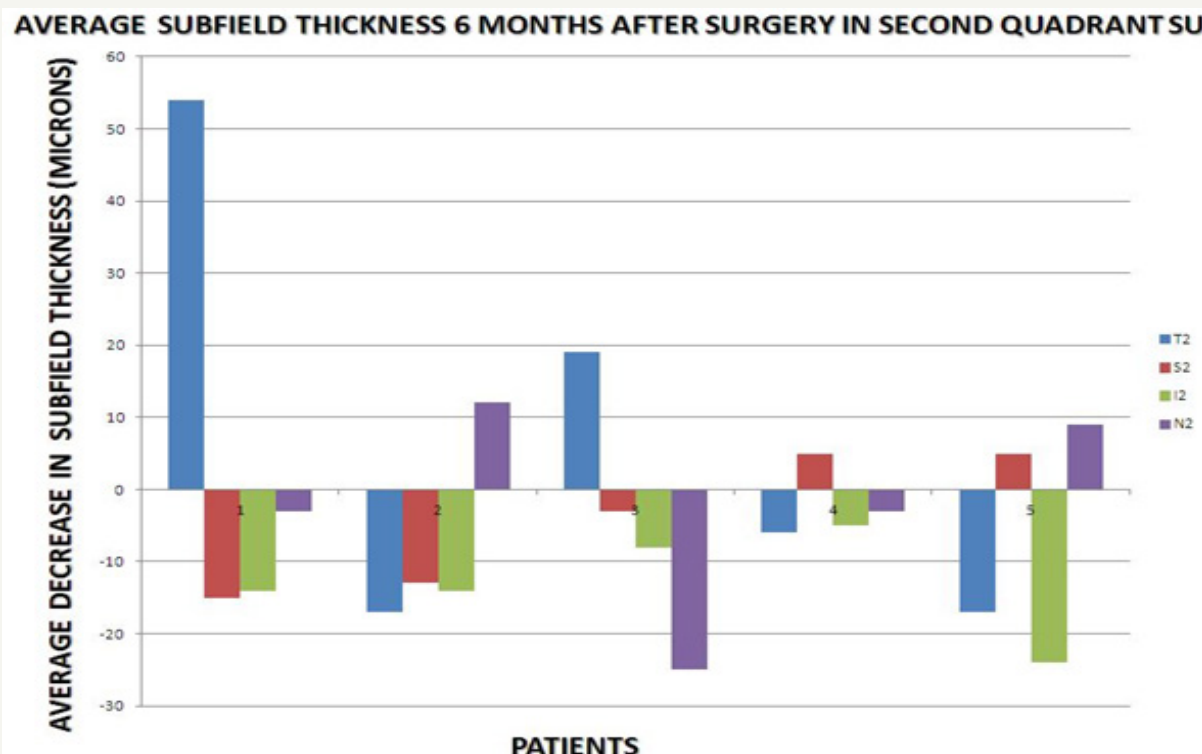

Figure 3: Shows the average subfield thickness change (microns) in the second quadrants at the end of 6 months follow up

\section{Case 5}

59 year old male had preoperative visual acuity of counting fingers 1 meter in left eye. Visual acuity at 6 month of follow up was 6/24 in left eye. OCT topographic mapping showed similar temporal irregularity (Figure 1 ) and first subfield thickness change from baseline after surgery at 6 months was -97 microns (T1), -32 microns (S1), -80 microns (I1) and -10 microns (N1) (Figure 2).

\section{Discussion}

Studies have shown that there is progressive change in the macular thickness and conspicuous inner retinal dimpling [1-5]. Diaz et al. [2] have shown morphologic correlation of focal nerve fiber layer atrophy and grasping site of the ILM which suggest that grasping the ILM can prove to be damaging. A comprehensive review of literature by Pichi et al. [1] suggest the earliest change in macula after ILM peeling is the postoperative swelling of arcuate retinal nerve fiber layer which is transient and disappears in 3 months time. This is followed by dimples in the inner retina as seen on OCT. It also suggested that there is evidence of postoperative foveal displacement towards the optic disk. Shortening of papillofoveal distance may be secondary to axonal transport and contractile change in retinal nerve fiber layer. This comprehensive evidence by Pichi et al. [1] appears to suggest that ILM peeling is traumatic and may have acute effects on nerve fiber layer. Focal ERG and micro perimetry studies suggest the role of Muller cell damage, reduced retinal sensitivity and incidence of micro-scotomas [5-7].
Ozdemir et al. [7] have also shown retinal sensitivity and fixation changes seen one year after ILM peeling for macular hole surgery using MP-1 micro perimetric study. Study showed postoperatively, there was a shift in the position of fixation point. The shift was correlated to the degree of visual improvement. The present small case series have shown that macular thickness changes were predominantly evident in the First subfield quadrant with trend towards downward slope of temporal area of macula as evident on topography morphologic map. One may speculate whether neuro sensory retina thickness variability in temporal and nasal sector of the macula can play a role.

Even though traumatic effects of ILM peeling is documented in literature, the visual improvement and increase success of surgery demands more research in modifying the technique and micro-gauge instrument. With evidence available in the literature regarding functional change, it is imperative that a larger prospective clinical trial is required to understand the long-term effect of ILM peeling relative to macular morphology and function.

\section{References}

1. Pichi F, Lembo A, Morara M, Veronese C, Alkabes M, et al. (2014) Early and late inner retinal changes after inner limiting membrane peeling. Int Ophthalmol 34(2): 437-446.

2. Diaz RI, Randolf JC, Sigler EJ, Calzada JI (2014) Intraoperative grasp site correlation with morphologic changes in the retinal nerve fiber layer after internal limiting membrane peeling. Ophthalmic Surg lasers Imaging Retina 45 (1): 45-49. 
3. Amouyal F, Shah SU, Pan CK, Schwartz SD, Hubschman JP (2014) Morphologic features and evolution of inner retinal dimples on optical coherence tomography after internal limiting membrane peeling. Retina 34(10): 2096-2102.

4. Baba T, Yamamoto S, Kimoto R, Oshitari T, Sato E (2012) Reduction of thickness of ganglion cell complex after internal limiting membrane peeling during vitrectomy for idiopathic macular hole. Eye 26(9): 11731180 .

5. Kumagai K, Hangai M, Larson E, Ogino N (2013) Progressive changes of regional macular thickness after macular hole surgery with internal limiting membrane peeling. Invest Ophthalmol Vis Sci 54(7): 4491-4497.

6. Tadayoni R, Svorenova I, Erginay A, Gaudric A, Massin P (2012) Decreased retinal sensitivity after internal limiting membrane peeling for macular hole surgery. Br J Ophthalmol 96(12): 1513-1516.

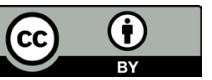

Creative Commons Attribution 4.0

International License

For possible submission use the below is the URL
7. Ozdemir H, Karacorlu M, Senturk F, Karacorlu SA, Uysal O (2010) Retinal sensitivity and fixation changes 1 year after triamcinolone acetonide assisted internal limiting membrane peeling for macular hole surgery--a MP-1 microperimetric study. Acta Ophthalmol 88(6): 222-227.

8. Thinda S, Shah RJ, Kim SJ (2015) Two-Year Anatomical and Functional Outcomes after Macular Hole Surgery: A Prospective, Controlled Study. Ophthalmic Surg Lasers Imaging Retina 46(9): 926-934.

9. Takamura Y, Tomomatsu T, Matsumura T, Arimura S, Gozawa M, et al. (2015) Correlation between central retinal thickness after macular hole surgery and visual outcome. Jpn J Ophthalmol 59(6): 394-400.

10. Hashimoto Y, Saito W, Fujiya A, Yoshizawa C, Hirooka K, et al. (2015) Changes in Inner and Outer Retinal Layer Thickness after Vitrectomy for Idiopathic Macular Hole: Implications for Visual prognosis 10(8): e0135925.

\section{Your subsequent submission with Crimson Publishers will attain the below benefits}

- High-level peer review and editorial services

- Freely accessible online immediately upon publication

- Authors retain the copyright to their work

- Licensing it under a Creative Commons license

- Visibility through different online platforms

- Global attainment for your research

- Article availability in different formats (Pdf, E-pub, Full Text)

- Endless customer service

- Reasonable Membership services

- Reprints availability upon request

- One step article tracking system 